\title{
David Oliver: Hearing loss in hospital
}

\author{
David Oliver consultant in geriatrics and acute general medicine
}

Berkshire

One in six people in England has hearing loss-around $42 \%$ of people over 50 and $71 \%$ of over 70 s. ${ }^{1}$ Increasing age brings greater risk of frailty, dementia, and functional impairment in daily activities, which may be compounded by hearing loss. ${ }^{23}$ Hospital patients with hearing loss are multiply disadvantaged if we're not attuned to their needs.

Quality of care may be jeopardised if we don't document and share knowledge of patients' pre-existing hearing loss. It can, for example, be a risk factor for developing delirium. ${ }^{4}$ It can make it harder for patients to understand instructions or information, which could in turn hinder physical examination, functional or cognitive assessment, and rehabilitation. Ineffective communication can leave clinical teams frustrated, and patients bewildered and excluded, as the ward round moves on.

Sometimes hearing loss can leave clinical teams thinking, wrongly, that a patient has significant cognitive impairment or depression. Countless times I've seen patients turn out to be far less confused than we initially thought, after a listening aid was used or when a family member arrived who was used to communicating with the patient. It's all too easy to write off patients' chances of recovery or benefit from treatment, or to underestimate their mental capacity for decision making, simply because of their deafness.

Outpatient consultations can also be fraught, for example, if a doctor is looking at a computer screen or patient notes, giving the patient less chance to lipread or see facial expressions. A patient may easily leave the consulting room having missed key information, without a good chance for doctors to check their understanding or for patients to raise concerns.

When patients are admitted to wards, too many hearing aids are still lost ${ }^{5}$ : some aren't being used or may have stopped working, sometimes simply for want of a battery. Clinical staff have only a sketchy idea of how to check that hearing aids are working or correctly inserted. ${ }^{6}$

\section{Effective patient contact}

Some basic good practice is outlined in toolkits and guides. ${ }^{78}$ We should sit or kneel at a patient's eye level, not tower above them. This is doubly important for people with hearing loss: it helps to avoid distracting background noise and ensure adequate lighting, and touching a patient on the shoulder or hand can signal that you want to speak. Slow, clear, face-to-face speech at eye level is preferable, sometimes with register lowered slightly. Shouting helps only rarely, and it can destroy confidentiality by broadcasting private conversations around a ward.

In select patients, simple manoeuvres can help, such as removing earwax, ${ }^{6}$ using written communication, or listening aids, which could easily be made available for each ward.

Get these basics wrong, and we risk providing a standard of care we wouldn't want for ourselves or our relatives. It's also upsetting for families when we do, especially when they've repeatedly passed on their concerns but keep finding the same problems when they visit.

Finally, for such patients contact with hospital provides opportunities to detect previously unrecognised hearing loss and steer people to the right services or to alert their GP. ${ }^{9} \mathrm{We}$ take this case finding approach for many other conditions, so why not for deafness?

Competing interests: See www.bmj.com/about-bmj/freelance-contributors. Provenance and peer review: Commissioned; not externally peer reviewed.

1 NHS England, Department of Health. Action plan on hearing loss. 23 Mar 2015. https:// www.england.nhs.uk/wp-content/uploads/2015/03/act-plan-hearing-loss-upd.pdf.

World Health Organization. World report on ageing and health. 2015. https://apps.who. int/iris/bitstream/handle/10665/186463/9789240694811_eng.pdf; jsessionid=45671EA1648EAAAB490D068DA1D0825E? sequence=1.

3 Clegg A, Bates C, Young J, etal . Development and validation of an electronic frailty index using routine primary care electronic health record data. Age Ageing 2016;45:353-60. https://academic.oup.com/ageing/article/45/3/353/1739750. 10.1093/ageing/afw039 26944937

4 Ahmed S, Leurent B, Sampson EL. Risk factors for incident delirium among older people in acute hospital medical units: a systematic review and meta-analysis. Age Ageing 2014;43:326-33. https://www.ncbi.nlm.nih.gov/pmc/articles/PMC4001175/. 10.1093/ageing/afu022 24610863

5 Oliver D. David Oliver: Admission should allow for patient aids. BMJ 2017;358:j3953. 10.1136/bmj.j3953 28928154

6 Middleton A, Niruban A, Girling G, Myint PK. Communicating in a healthcare setting with people who have hearing loss. BMJ 2010;341:c4672. 10.1136/bmj.c4672 20880905 King's Fund. Nursing toolkit. https://www.kingsfund.org.uk/sites/default/files/media/Action\% 20on\%20Hearing\%20Loss,\%20Nursing\%20Toolkit.pdf.

8 Action on Hearing Loss. Communicating well with residents who have hearing loss. https: //www.actiononhearingloss.org.uk/-/media/ahl/how-we-help/health-care-professionals/ a1422_info-sheet_communicating-well-with-residents-who-have-hearing-loss_v03.pdf. 
9 NHS England. Commissioning services for people with hearing loss: a framework for clinical commissioning groups. 15 Jul 2016. https://www.england.nhs.uk/publication/ commissioning-hearing-loss-framework/.
Published by the BMJ Publishing Group Limited. For permission to use (where not already granted under a licence) please go to http://group.bmj.com/group/rights-licensing/ permissions 